\title{
The Crazyist Metaphysics of Mind
}

\author{
Eric Schwitzgebel \\ Department of Philosophy \\ University of California \\ Riverside, CA 92521 \\ eschwitz at domain: ucr.edu
}

July 12, 2013 


\title{
The Crazyist Metaphysics of Mind
}

\begin{abstract}
:
Crazyism about $\mathrm{X}$ is the view that something that it would be crazy to believe must be among the core truths about X. In this essay, I argue that crazyism is true of the metaphysics of mind. A position is "crazy" in the intended sense if it is contrary to common sense and we are not epistemically compelled to believe it. Crazyism about the metaphysics of mind can thus be treated as the conjunction of two sub-theses: (1.) that something contrary to common sense must be among the core truths of the metaphysics of mind and (2.) that whatever that true thing is, we are not epistemically compelled to believe it. I defend the first thesis on grounds of the probable incoherence of folk metaphysics, from which follows that any fully fleshed-out metaphysics will inevitably conflict with some piece of that incoherent story. I defend the second thesis on three grounds: peer disagreement, lack of a compelling method for resolving metaphysical disputes about the mind, and the dubiousness of the general cosmological claims with which metaphysical claims about the mind are entangled.
\end{abstract}




\section{The Crazyist Metaphysics of Mind}

Mysterians about the mind - Colin McGinn (1989, 2004), Noam Chomsky (2009) - say that we

will probably never know how conscious experience arises from the brain. But here's one thing we do know, according to them: Whatever the process involved, it's "natural". No hand of God, no immaterial souls required. But I wonder, if we know as little as they say, why rule out deities and immaterial souls? If the soul seems a strange and unnatural thing, alien to our science, well, our science is an impoverished tool for penetrating the mysteries of the universe, they say. A turtle might find strange and unnatural a container ship and might find almost ethereal a schedule of amortization. If we are but somewhat upgraded turtles, our sense of unnaturalness is no rigorous index of reality.

In this essay I propose a more skeptical mysterianism about the mind than that of McGinn and Chomsky. On my view, it is probably the case that something it would be crazy to believe - something bizarre and undeserving of credence - is among the core metaphysical truths about the mind. And immaterial souls aren't ruled out.

i.

Bizarre views are a hazard of metaphysics. The metaphysician starts, seemingly, with some highly plausible initial commitments or commonsense intuitions - that there is a prime number between 2 and 5, that I could have had eggs for breakfast, that squeezing the clay statue would destroy the statue but not the lump of clay. She thinks long and hard about what, exactly, these claims imply. In the end, she finds herself positing a realm of abstract Platonic entities, or the 
real existence of an infinite number of possible worlds, or a huge population of spatiotemporally coincident things on her mantelpiece. ${ }^{1}$ I believe that there is not a single broad-ranging exploration of the fundamental issues of metaphysics that doesn't, by the end, entangle its author in seeming absurdities (sometimes advertised as "surprising conclusions"). Rejection of these seeming absurdities then becomes the commonsense starting point of a new round of metaphysics, by other philosophers, which in turn generates a complementary bestiary of metaphysical strangeness. Thus are philosophers happily employed.

I see three possible explanations of why philosophical metaphysics is never thoroughly commonsensical:

First possible explanation. A thoroughly commonsensical metaphysics wouldn't sell. It would be too boring, perhaps. Maybe a famous philosopher can't say only obvious things. Or maybe it would lack a kind of elegant serviceability or theoretical panache. Or maybe it would conflict too sharply with what we think we know from science. The problem with this explanation is that there should be at least a small market for a thoroughly commonsensical philosophy, even if that philosophy is gauche, tiresome, and scientifically stale. Common sense might not be quite as fun as Nietzsche's eternal recurrence (1883-1888/1967) or Leibniz's windowless monads (1714/1989); it might not be as elegantly useful as Lewis's possible worlds (1986) or as scientifically current as [insert ever-changing example]; but a commonsensical metaphysics ought to be attractive to at least a certain portion of philosophers. At least it ought to command attention as a foil. It oughtn't be so downmarket as to be entirely invisible.

\footnotetext{
${ }^{1}$ For example, Frege 1884/1953, 1918/1956 (though see Reck 2005); Lewis 1986; Yablo 1987.
} 
Second possible explanation. Metaphysics is very difficult. A thoroughly

commonsensical metaphysics is out there to be discovered; we simply haven't found it yet. If all goes well, someday someone will piece it all together, top to bottom, with no serious violence to common sense anywhere in the system. I fear this is wishful thinking against the evidence. In the next several sections I will discuss the case of the metaphysics of mind in particular.

Third possible explanation. Common sense is incoherent in matters of metaphysics. Contradictions thus inevitably flow from it, and no coherent metaphysical system can respect it all. Although ordinary common sense serves us fairly well in practical maneuvers through the social and physical world, common sense has proven an unreliable guide in cosmology and probability theory and microphysics and neuroscience and macroeconomics and evolutionary biology and structural engineering and medicine and topology. If, as it seems to, metaphysics more closely resembles these latter endeavors than it resembles reaching practical judgments, we might excusably doubt the dependability of common sense as a guide to metaphysics. ${ }^{2}$ Undependability doesn't imply incoherence, of course. But it seems a natural next step in this case, and it would tidily explain the historical fact at hand.

On the first explanation, we could easily enough invent a thoroughly commonsensical metaphysical system if we wanted one, but we don't want one. On the second explanation, we do want one, or enough of us do, but we haven't yet managed to construct it. On the third

${ }^{2}$ Critiques of the role of common sense or philosophical intuition as a guide to metaphysics and philosophy of mind can be found in, for example, Churchland 1981; Stich 1983; Gopnik and Schwitzgebel 1998; Kornblith 1998; Dennett 2005; Ladyman and Ross 2007; and Weinberg, Gonnerman, Buckner, and Alexander 2010. Hume 1740/1978 and Kant $1781 / 1787 / 1998$ are also interesting on this issue, of course. Even metaphilosophical views that treat metaphysics largely as a matter of building a rigorous structure out of our commonsense judgments often envision conflicts within common sense so that the entirety of common sense cannot be preserved: e.g., Ayer 1967; Kriegel 2011. 
explanation, we can't have one. I hope you'll agree with me that the third has at least some prima facie merit.

Common sense might be culturally variable. So whose common sense do I take to be at issue in this argument? I suspect it doesn't matter. All metaphysical systems in the philosophical canon, I'm inclined to think, conflict both with the common sense of their milieu and with current Western common sense. Much of the human worldview is stable over time, especially in Western societies since the early modern period. Eternal recurrence, windowless monads, and the real existence of an infinitude of possible worlds were never part of any society's common sense.

Some readers will disagree about the existence of the phenomenon I aim to explain; they will think that there is a thoroughly commonsensical metaphysics on the market. To some extent, I'm simply taking as a premise that there is none, and I'm inviting you to agree based on your own reading of historical and contemporary metaphysics. Maybe the premise will appeal better, though, if I highlight its intended scope. It concerns only broad-ranging explorations of fundamental metaphysical issues, especially the issues where seeming absurdities congregate: mind and body, causation, identity, the catalogue of entities that really exist. Some skating treatments and some deep treatments of narrow issues might dodge the charge.

Who might count as a thoroughly commonsensical metaphysician? Aristotle, I've sometimes heard. Or Scottish “common sense” philosopher Thomas Reid. Or G.E. Moore, famous for his "Defence of Common Sense" (1925). Or “ordinary language” philosopher P.F. Strawson. But Aristotle didn't envision himself as developing a commonsensical view: In the introduction to the Metaphysics Aristotle says that the conclusions of sophisticated inquiries such as his own will often seem "wonderful" to the untutored and contrary to their initial opinions $\left(4^{\text {th }}\right.$ 
c. BCE/1928, 983a; $\theta \alpha v \mu \alpha \sigma \tau o ́ v$ : wonderful in the sense of tending to cause wonder, or amazing); and Aristotle generally conceives his project as in part to distinguish the true from the false in common opinion. Moore, though fierce in wielding common sense against his foes, seems unable to preserve all commonsense commitments when he develops his positive views in detail, for example in his waffling about "sense data" $(1922,1953,1957)$. Strawson struggles similarly, especially in his 1985 book, where he can find no satisfactory commonsense account of mental causation. Reid I will discuss briefly in section vi.

The argument of this section is an empirical explanatory or "abductive" argument. The empirical fact to be explained is that all metaphysical systems defy common sense. An attractive possible explanation of this fact, I submit, is that common sense is incoherent on matters metaphysical, so that no self-consistent and detailed metaphysical system can satisfy all commonsense constraints.

ii.

Let's call a position bizarre if it's contrary to common sense. And let's say that a position is contrary to common sense just in case a majority of people without specialized training on the issue confidently, but perhaps implicitly, believe it to be false. Claims about common sense are empirically testable, but not always straightforwardly so. It might, for example, sometimes be difficult to clarify the target claim - e.g., that there is a "Platonic realm" - without either mangling the target view or altering the respondent's attitude toward it; and what is implicitly believed may be only tenuously connected to explicit questionnaire responses. The best firstpass measure of commonsensicality might be specialists' own impressions about the degree of 
conflict between positions in their field and non-specialists' attitudes, as remembered from their training and reinforced in their teaching, with contentious cases to be referred for more systematic empirical study.

To call a position bizarre is not necessarily to repudiate it. Relativity theory is bizarre. Various bizarre things are true about the infinite. It's bizarre yet true that a black and white disk will look colored if spun at the right speed. Common sense errs, and we can be justified in thinking so. However, we are not ordinarily justified in believing bizarre things without compelling evidence. In the matters it traverses, common sense serves as an epistemic starting point that we reject only with sufficient warrant. To believe something bizarre on thin grounds for example, to think that the world was created five minutes ago, or that you are constantly cycling through different immaterial souls, or that the universe was sneezed out by the Great Green Arkleseizure (assuming you have no special warrant for these views) - seems crazy. I stipulate, then, the following technical definition of a crazy position: A position is crazy if it's bizarre and we are not epistemically compelled to believe it.

One needn't, of course, be clinically insane to accept crazy views, and not all crazy views are as crazy as the three just mentioned. Many philosophers and some scientists embrace positions contrary to common sense and for which the evidence is less than compelling. In fact, to convert a position from crazy to merely bizarre might be the highest form of academic success. Einstein, Darwin, and Copernicus (or maybe Kepler) all managed the conversion - and in the case at least of Copernicus common sense eventually relented. Intellectual risk-takers nurture the crazy and see what marvels bloom. The culture of contemporary Anglophone academia, perhaps especially philosophy, overproduces craziness like a plant produces seeds. 
Crazyism about a topic, then, is the view that something crazy must be among the core truths about that topic. Crazyism can be justified when we have good reason to believe that one among several bizarre views must be true but where the balance of evidence leaves no individual view decisively supported over all the others. We might find ourselves rationally compelled to believe that either T1, T2, T3, or T4 must be true, where each of the T's is crazy.

Crazyism might be justified in interpreting quantum mechanics. The "many worlds" and "many minds" interpretations, for example, sharply conflict, it seems, with ordinary common sense. ${ }^{3}$ And it also seems that the balance of evidence does not compellingly favor either of these views over all competitors. Thus, the views are crazy in the sense defined. If the same holds for all viable interpretations of quantum mechanics, then crazyism would be warranted in that domain. ${ }^{4}$

I will argue below that crazyism is warranted in the metaphysics of mind. I will argue that any well developed materialist metaphysics will be crazy, in the intended sense of the term. I will argue the same for any well developed dualist metaphysics. And the same for idealism (well developed or not). And the same for positions that reject all three of these views or aim to reconcile or compromise among them. But some metaphysical theory of this sort must be true that is, either some form of materialism, dualism, or idealism must be true or some sort of rejection or compromise approach must be true. So something crazy must be among the core truths in the metaphysics of mind.

${ }^{3}$ DeWitt, for example, writes: I still recall vividly the shock I experienced on first encountering this multiworld concept. The idea of $10^{100+}$ slightly imperfect copies of oneself all constantly splitting into further copies, which ultimately become unrecognizable, is not easy to reconcile with common sense (1970, p. 33).

${ }^{4}$ Recent reviews of the difficulties in settling among various bizarre interpretations include Penrose 2004; Wallace 2008. 
Materialism has enjoyed such a good vogue in Anglophone philosophy recently that it might not seem to be crazy. And, indeed, it is not part of my thesis that materialism is crazy. Rather, my thesis is that any well developed materialist metaphysics will be crazy. Maybe materialism per se is sufficiently vague and noncommittal as to provide no shock to common sense. However, I do think that working out the details of a materialist view will inevitably force choices among major violations of common sense, and no one conjunction of violations will merit belief over all rivals.

The materialist (or "physicalist") position is difficult to characterize precisely. ${ }^{5}$ This might be a problem for the view - though if so, I'm inclined to think that it's just a manifestation of a more general problem that I'll discuss in section xii. As a working approximation, let's characterize materialism as the view that everything in the universe is composed of, or reducible to, or most fundamentally, material stuff, where "material stuff" means things like elements of the periodic table and the various particles or waves or fields that interact with or combine to form such elements, whatever those particles, waves, or fields might be, as long as they are not themselves intrinsically mental. The two historically most important competitor positions are idealism and substance dualism, both of which assert the existence of an immaterial soul.

It's a striking sociological fact about materialism that, after a long history as a minority position, suddenly in the 1950s and 1960s a new generation of Anglophone philosophers of mind adopted it as orthodoxy - Hilary Putnam, Jerry Fodor, Daniel Dennett, David Lewis, J.J.C.

\footnotetext{
${ }^{5}$ See, e.g., Hempel 1980; Chomsky 1995, 2009; Montero 1999; Stoljar 2010.
} 
Smart, Fred Dretske, Donald Davidson, John Searle, David Armstrong, Sydney Shoemaker, and many others. ${ }^{6}$ Maybe this sudden generational shift reflected progress, like the progress of science. It's also possible that it was the broad swing of a pendulum. We don't yet have, I suspect, the historical distance to know.

iv.

Materialism per se might be contrary to common sense.

Materialism is almost certainly a minority view in our current culture and historically across human cultures. People have a widespread, and maybe deep, tendency to believe that they are more than just material stuff. I doubt most readers need convincing of this sociological fact, but for completeness see this note. ${ }^{7}$ Not all unpopular views violate common sense, however, by my definition of "common sense" (in section ii): It depends how confidently the opposing view

${ }^{6}$ Although Searle rejects the dualism-materialism distinction, I believe he is materialist in the broad sense of the previous paragraph. See, e.g., Searle 1995, pp. 6-7. Putnam is also a somewhat complicated case.

${ }^{7}$ In the General Social Survey of Americans in 2010 (http://www3.norc.org/GSS+Website), $72 \%$ of respondents reported believing in life after death and $17 \%$ reported disbelieving; also, $75 \%$ reported believing in God, $11 \%$ reported belief in an impersonal "Higher Power", and only 3\% reported atheism. We can probably safely assume that most contemporary American theists are not materialists (though some may be: Baker 1995; Murphy 2006). Some other industrialized Western nations are more secular than the U.S., but even in those societies religiosity is widespread (Zuckerman 2007), and religiosity or belief in entities not tolerated by materialism might even be something like a cultural universal (Brown 1991; McCauley 2000; Boyer 2001). Paul Bloom (2004) has argued on developmental and cross-cultural grounds that it is innately natural to human beings to think of mental life as the product of an immaterial soul, even if some of us reject dualism on an "airy intellectual level" (see also Richert and Harris 2006; Hodge 2008; Slingerland and Chudek 2011). In David Bourget's and David Chalmers' 2009 PhilPapers survey of faculty in leading Anglophone philosophy departments, $62 \%$ of respondents reported accepting atheism and another $11 \%$ reported "leaning toward" it. Yet even in this remarkably secular group, only 35\% reported accepting and $22 \%$ reported leaning toward physicalism (http://philpapers.org/surveys). See also Bourget and Chalmers forthcoming. 
is held. In the case of materialism per se - that is, materialism abstractly considered, prior to theoretical choices about how to develop it - I find it difficult to gauge, without more systematic empirical evidence, how confident, stable, and widespread its rejection is among non-specialists.

Certain apparent consequences of materialism per se might be robustly bizarre. This would explain anti-materialist philosophers' fondness of these consequences as an argumentative lever. Consider Leibniz's mill:

Moreover, we must confess that the perception, and what depends on it, is inexplicable in terms of mechanical reasons, that is, through shapes and motions. If we imagine that there is a machine whose structure makes it think, sense, and have perceptions, we could conceive it enlarged, keeping the same proportions, so that we could enter into it, as one enters into a mill. Assuming that, when inspecting its interior, we will only find parts that push one another, and we will never find anything to explain a perception (1714/1989, p. 215 [§ 17], emphasis in original).

When the view is so vividly displayed, something in most people, I think, resists the materialist's reduction of experience to bumping matter. If you see nothing bizarre in Leibniz's mill, maybe science and philosophy have stolen a bit of your common sense. Other thought experiments work similarly. Consider "zombies": It seems we can conceive of entities physically and behaviorally identical to us but entirely lacking conscious experience or "phenomenology". 8 Conceivability may or may not imply possibility; the thought experiment has power regardless. It draws the mind to think that materialism leaves something out. Consider also Frank Jackson's (1986) "Mary", the super-scientist confined to a black and white room, who can seemingly learn

\footnotetext{
${ }^{8}$ See, e.g., Campbell’s 1970 “imitation man”; Kirk 1974, 2005; Chalmers 1996.
} 
all the physical facts about the world, including about the physics and physiology of color perception, yet remain ignorant of some experiential facts, such as what it's like to see red. Such thought experiments seem to tap into a folk psychological "explanatory gap" between physical properties or events and the colorful phenomenology of conscious experience; people seem to seek something immaterial to bridge the two. ${ }^{9}$ Maybe, then, it's part of common sense to suppose that any materialist metaphysics will be incomplete.

V.

Regarding materialism per se, I think it's unclear exactly where the boundaries of common sense lie. However, I believe that any well developed materialist metaphysics of mind - that is, any plausible materialist metaphysics with specific commitments about the necessary and sufficient conditions for possessing mental states - will inevitably astound common sense. If it seems otherwise in reading Putnam or Lewis or Smart, that's because materialist philosophers are often vague on the issues from which bizarreness springs.

If materialism per se conflicts with majority belief and presents a seeming explanatory gap, all the more so, it seems likely, will specific materialist accounts of consciousness. Francis Crick (1994), for example, equates human consciousness with synchronized 40-hertz oscillations in the subset of neurons corresponding to an attended object. Nicholas Humphrey $(1992,2011)$ equates consciousness in general with reentrant feedback loops in an animal's sensory system. Such views are not just tepidly unintuitive. Crick and Humphrey both repeatedly emphasize that non-specialists vigorously resist their views. Common sense fights them hard. Common sense

\footnotetext{
${ }^{9}$ See, e.g., Levine 1983, 2001; Chalmers 1996; Ramsey 2006; Robbins and Jack 2006.
} 
fights them hard not because of the details, I suspect, but rather because the details vividly reveal the bizarreness of the general project.

Another reason to anticipate sharp conflicts between common sense and well developed forms of materialism is that, as I mentioned in section i, common sense has tended to fare poorly beyond practical contexts. A pessimistic induction suggests that common sense will be grossly wrong about some major aspect of the metaphysics of mind too - especially if we consider implications beyond the usual run of daily life, implications for pathological and science fiction and deep-sea cases. Furthermore, early returns in the empirical study of folk attributions of mental states to corporations, robots, and peculiar entities suggest that folk psychology is not a paradise of rigorously principled materialism. ${ }^{10}$ Philosophers friendly to materialism should be eager, like Crick and Humphrey, to abandon poorly founded aspects of common sense. ${ }^{11}$

Materialists have reason to suspect serious flaws in the folk psychological materials from which commonsense judgments must ultimately be constructed.

I will now illustrate by discussing two specific issues on which I suspect well developed materialist views will be forced into bizarreness.

${ }^{10}$ Gray, Gray, and Wegner 2007; Knobe and Prinz 2008; Huebner, Bruno, and Sarkissian 2010; Sytsma and Machery 2010; Buckwalter and Phelan 2011; Fiala, Arico, and Nichols 2011; Phelan, Arico, and Nichols forthcoming. For example: Fiala, Arico, and Nichols argue for a dual-process explanation of the folk psychology of consciousness attribution. They postulate a "low road" cognitive process that attributes consciousness to entities with eyes, non-inertial motion trajectories, and apparently contingent interaction, and they postulate a "high road" cognitive process grounded in deliberate reasoning, including consciously endorsed theories. Suppose this dual-process model is broadly correct. One might doubt that either the low-road or the high-road process will map nicely onto any plausible well developed materialist metaphysics. Even if one process does by happy circumstance map well, the other process - or still some third cognitive mechanism - might well still prove powerful enough to generate conclusions contrary to the first and yet felt to have the force of common sense.

${ }^{11}$ See, e.g., Churchland 1981; Stich 1983; Kim 1998; Metzinger 2003; Dennett 2005; Mandik and Weisberg 2008. 
First illustration of the likely bizarreness of materialism: Mad pain, Martian pain, and beer can pain. Who in the universe can feel pain? To judge from the literature, there are currently four viable materialist answers: beings with brains like our own, beings that react to the world in patterns similar to our own, some hybrid view, or some further-mysterious-property view. To evoke a further mysterious property is not to have a well developed view in the sense I intend, so let's set such gestures aside. The remaining three views all appear to have bizarre consequences. To insist on brains, that is, on similarity to our own interior biophysical configuration, seems terribly chauvinistic if we hope to have the whole universe in view and not just our little section of it: Couldn't a being - an octopus or a space alien? - feel pain despite stark interior differences from us? ${ }^{12}$ Suppose space aliens arrive tomorrow. They decode English from our television broadcasts and converse fluently with us, behaving much as we doincluding withdrawing, screaming, writhing, protesting, avoiding, and revenging when damaged with sharp objects. They write novels and medical treatises about their agonies, and there's no reason to doubt their sincerity. They look and act much like us, but inside, they operate by hydraulics, or lasers, or maybe even via the interaction of a billion writhing bugs. I venture that it would seem bizarre to most people - a weird philosopher's quibble - to insist that to really be experiencing pain they must also have brains like our own. The aliens might be integrated into our schools and marriages; one can imagine the outraged charges of speciesism.

As I've described the case, these aliens are functionally similar to us, similar in having pain states that play human-like causal roles in their mental economies. Thus functionalism beckons: Maybe the beings in the universe who experience pain are just the beings in the

12 This thought is central to early functionalist arguments against identity theory materialism, e.g., Putnam 1965; Fodor 1974. For discussion and criticism see Bechtel and Munsdale 1999; Shapiro and Polger 2012. 
universe who have states that play the causal role of pain, however those states are physically constituted. But such functionalism also has bizarre consequences, as highlighted by Ned Block (1978/2007) and John Searle (1980, 1984, 1992). If mentality is all about causal role, then weird assemblies of beer cans and wire, powered by windmills and controlling a marionette, could presumably have conscious experience if arranged the right way; and systems composed of rulebooks, slips of paper, and monolingual English speakers could understand Chinese. Such systems could presumably, at least in principle, produce arbitrarily complex functional patterns of behavior, outwardly indistinguishable (except in speed) from the behavior of commonsensically conscious beings like dogs or babies or even adult humans. Similarly bizarre are some consequences on the flip side: If pain is all about causal role, then no one could feel pain without possessing some state that is playing the normal causal role of pain. But it seems simple common sense that one person might enter an experiential state under one set of conditions and might tend to react to it in one way, while another person, or the same person later, might tend to enter the same type of experiential state under very different conditions and have very different reactions. Madness, pathology, disability, drugs, brain stimulation, personality quirks, and maybe radical Sartrean freedom, can amply scramble, it seems, the actual and counterfactual causes and effects of any experiential state. So while the brain-oriented view seems to be neural chauvinism, insisting that pain is all about causal role appears to be functional chauvinism.

Maybe both views are too simple. Maybe we can thread the needle by hybridizing: Beings who experience pain are beings in states with one of a variety of possible biological or physical configurations - just those biological or physical configurations that normally play the causal role of pain, even if things sometimes aren't quite normal. The word "normally" here can 
be understood in various ways. Maybe what matters is that the being possesses some type of physical or biological configuration that plays the required causal role in the right population (e.g., Lewis 1980). Or maybe what matters is that the configuration played that role, or was selected to play that role, in the developmental or evolutionary history of the organism (e.g., Dretske 1995; Tye 1995, 2009). Either way, you're in pain because you're in the physical state that normally plays the causal role of pain for you or for your group, regardless of whether that state happens to be playing exactly that role for you right this instant.

What's central to such appeals to normality is that pains no longer "supervene" locally: Whether you're in pain now depends on how your current biophysical configuration is seated in the broader universe. It depends on who else is in your group or on events in the past. If normality turns upon the past, then you and I might be molecule-for-molecule identical with each other now, screaming and writhing equally, equally cursing our maker, but because of differences in personal or evolutionary history, you're in pain and I'm not. This would seem to be action at a historical distance. If pain depends, instead, on what is currently normal for your species or group, that could change with selective genocide or with a speciation event beyond your ken. Strange forms of anesthesia! While local nonsupervenience is plausible for relational properties - whether I have an uncle, whether I'm thinking of coffee cup A or qualitatively identical coffee cup B - it is bizarre for pain.

The issue appears to present a trilemma for the materialist: Either accept neural chauvinism (no Martian pain), accept flat-footed functionalism (beer can pain and no mad pain), or deny local supervenience (anesthesia by speciation or genocide). Maybe some materialist view can evade all three horns; they don't seem logically exhaustive. But if so, I don't see the 
view out there yet. It is, I think, a reasonable guess that no plausible, well developed materialist view can simultaneously respect all our commonsense judgments about this cluster of issues. ${ }^{13}$

\section{Second illustration of the likely bizarreness of materialism: The consciousness of the}

United States. It would be bizarre to suppose that the United States has a stream of conscious experience distinct from the conscious experiences of the people who compose it. I hope you'll agree. $^{14}$ (By "the United States" here, I mean the large, vague-boundaried group of people who are compatriots, sometimes acting in a coordinated manner, and maybe some portion of their material surroundings.) Yet it's unclear by what materialist standard the United States lacks consciousness. Nations, it would seem, represent and self-represent. They respond (semi)intelligently and self-protectively, in a coordinated way, to opportunities and threats. They gather, store, and manipulate information. They show skillful attunement to environmental inputs in warring and spying on each other. Their subparts (people and subgroups of people) are massively informationally interconnected and mutually dependent, including in incredibly fancy self-regulating feedback loops. These are the kinds of capacities and structures that materialists typically regard as the heart of mentality. ${ }^{15}$ Nations do all these things via the behavior of their

${ }^{13}$ See also Adams and Dietrich 2004. See Aydede 2009 and Hill 2009 for rather different arguments that the folk metaphysics of pain is incoherent. See Schwitzgebel in preparation-b for further illustration of the bizarreness of Lewis's approach to pain.

${ }^{14}$ Admittedly, the willingness of English-language speakers to ascribe mental states of various sorts to corporate entities is empirically complex. See Knobe and Prinz 2008; Sytsma and Machery 2009; Arico 2010; Huebner, Bruno, and Sarkissian 2010; Phelan, Arico, and Nichols forthcoming.

${ }^{15}$ E.g., Fodor 1987, 1990; Dennett 1987, 1991; Churchland 1984/1988; Dretske 1988, 1995; Lycan 1996; Tononi 2004; Carruthers 2005; Rosenthal 2005; Hill 2009; Humphrey 2011. Even materialists who emphasize the identity of mental states and brain states will normally see functional or causal structures of this sort as what it is that makes brain states the kinds of states that are conscious while the internal states of, say, a toaster are not: e.g., Armstrong 1968; Bechtel and Mundale 1999. Searle $(1984,1992)$ seems to be an exception to the tendency described here, though I find his positive position on the biological causes of consciousness too indeterminate in its commitments to fully evaluate on the present issue. 
subparts, of course; but on materialist views individual people also do what they do via the behavior of their subparts. A planet-sized alien who squints might see individual members of the United States as so many buzzing pieces of a somewhat diffuse body consuming bananas and automobiles, invading Iraq, exuding waste.

Even if the United States still lacks a little something needed for consciousness, it seems we ought at least hypothetically to be able to change that thing, and so generate a stream of experience. We presumably needn't go nearly as far as Block does in his famous "Chinese nation" example (1978/1991) - an example in which the country of China implements the exact functional structure of someone's mind for an hour - unless we suppose, bizarrely, that consciousness is only possible among beings with almost exactly our psychology at the finest level of functional detail. If we are willing to attribute consciousness to relatively unsophisticated beings (frogs? rabbits?), well, it seems that the United States can, and does sometimes, act with as much coordination and intelligence, if on a larger scale.

One might insist that specific details of biological implementation are essential to consciousness in any possible being - for example, specific states of a unified cortex with axons and dendrites and ion channels and all that - and that broadly mammal-like or human-like functional sophistication alone won't do. However, as I argued regarding pain, it seems bizarrely chauvinistic to regard consciousness as only possible in beings with internal physical states very similar to our own, regardless of outwardly measurable behavioral similarity. Or is there some specific type of behavior that all conscious animals exhibit but that the United States, perhaps slightly reconfigured, could not exhibit, and that is a necessary condition of consciousness? It's hard to see what that behavior could be. Is the United States simply not enough of an "entity" in the relevant sense? Well, why not? What if we all held hands? 
In his classic early statement of functionalism, Putnam (1965) simply rules out, on no principled grounds, that a collection of conscious organisms could be conscious. He didn't want his theory to result in swarms of bees having collective conscious experience, he says. But why not? Maybe bee swarms are dumber and represent less than do individual bees - arguably committees collectively act and collectively represent less than do their members as individuals but that would seem to be a contingent, empirical question about bees. To rule out swarm consciousness a priori, regardless of swarm behavior and swarm structure, seems mere prejudice against beings of radically different morphology. Shouldn't a well developed materialist view eventually jettison unprincipled folk morphological prejudices? We resist, perhaps, attributing consciousness to noncompact beings and to beings whose internal mechanisms we can see - but most materialist theories appear to imply, and probably part of common sense also implies, that such differences aren't metaphysically important. The materialist should probably expect that some entities to which it would seem bizarre to attribute conscious experience do in fact have conscious experience. If materialism is true, and if the kinds of broadly functional capacities that most materialists regard as central to conscious mentality are indeed central, it might be difficult to dodge the conclusion that the United States has its own stream of conscious experience, in addition to the experiences of its individual members. ${ }^{16}$

That's the kind of bizarreness I'm talking about. These two examples illustrate it, but if one or both examples fail, I hope that the general point is still plausible on broad, inductive grounds. The more we learn about cosmology, microphysics, mathematics, and other such

${ }^{16}$ See also Strawson 1959, p. 113-115; Edelman 2008, p. 431-433; Koch 2012, p. 131134; Huebner forthcoming. On group intentionality without (necessarily) group consciousness see Gilbert 1989; Austen Clark 1994; Bratman 1999; Wilson 2004; Tuomela 2007; Searle 2010; List and Pettit 2011; Huebner forthcoming. For further development of the ideas in this section, see Schwitzgebel in preparation-a. 
foundational matters, both cosmic and a priori, the grosser the violations of common sense seem to become. The materialist should expect no lesser weirdness from the metaphysics of mind.

vi.

One alternative to materialism is dualism, the view that people are not wholly material entities but rather possess immaterial souls in addition to their material bodies. ${ }^{17}$ (By "dualism", unqualified, I mean substance dualism, which posits an immaterial soul. "Property dualism" I will discuss briefly below.) Although dualism has merits as a first pass at a commonsense metaphysics of mind, from the $17^{\text {th }}$ century to the present, the greatest philosophers of the Western world have universally found themselves forced into bizarre views when attempting to articulate the metaphysics of immateriality. I regard this history as significant empirical evidence that a well developed metaphysics of substance dualism will unavoidably be bizarre.

Attempts at commonsense dualism founder, it seems, on at least two broad issues: the causal powers of the immaterial mind and the class of beings with immaterial minds.

The causal powers issue can be posed as a dilemma: Does the immaterial soul have the causal power to affect material entities like the brain? If yes, then material entities like neurons must be regularly and systematically influenced by immaterial events. A neuron must be caused to fire not just because of the chemical, electrical, and other physical influences on it but also because of immaterial happenings in spiritual substances. And that forces a subsidiary choice.

17 "Immaterial soul" is intended here in a fairly broad but traditional sense. By this criterion, some metaphysical systems that call themselves substance dualist, notably Lowe's (2008), do not qualify. Despite Lowe's choice of label his system is very different from traditional substance dualist approaches and for current purposes is probably better conceived as a compromise position. 
Maybe events in the immaterial realm transfer some physical or quasi-physical push that makes the neuron behave other than it would without that immaterial push. But that seems contrary to both ordinary ideas and mainstream scientific ideas about the sorts of events that can alter the behavior of small, material, mechanistic-seeming things like the subparts of neurons. Alternatively, maybe the immaterial somehow causally operates on the material despite the fact that material events would transpire in exactly the same way absent that influence. That seems at least as strange a view. Suppose, then, the other horn of the dilemma: The immaterial soul has no causal influence on material events. If immaterial souls do anything, they engage in rational reflection. On a no-influence view, such rational reflection could not causally influence the movements of the body. You can't make a rational decision that has any effect on the physical world. This again seems bizarre by the standards of ordinary common sense. I've rolled quickly here over some complex issues, but I hope that the informed reader will find that it rings true to say that dualists have perennially faced trouble accommodating the full range of commonsense opinion on mental-physical causation, for approximately the reasons outlined. ${ }^{18}$

The scope of mentality issue can be expressed as a quadrilemma. Horn 1: Only human beings have immaterial souls. Only we have afterlives. Only we have religious salvation. There's a cleanliness to the idea. But if the soul is the locus of conscious experience, then this view has the result that dogs are mere machines, with no consciousness, no pains, no sense experiences; there's nothing it's like to be a dog, any more than there's something it's like to be a toy robot. And that seems bizarre. Horn 2: Everybody and everything is in: humans, dogs, frogs, worms, viruses, carbon chains, lone hydrogen ions in outer space - we're all conscious! That view seems bizarre too. Horn 3: There a line in the sand. There's a sharp demarcation

\footnotetext{
${ }^{18}$ Patterson 2005 usefully compares historical and recent approaches to this issue.
} 
somewhere between beings with conscious experiences and those with no conscious experiences. But that seems weird, too: Across the spectrum of animals there's a smooth gradation of psychological capacities. Given this smooth gradation, how could there be a sharp line between the ensouled and unensouled creatures? What, toads in, frogs out? Grasshoppers in, crickets out? If the immaterial soul is the locus of conscious experience, it ought to do some work; there ought to be big psychological differences between creatures with and without souls. But the only remotely plausible place it seems, to draw a sharp line is between human beings and all the rest and that puts us back on Horn 1. Horn 4: Maybe we don't have to draw a sharp line. Maybe having a soul is not an on-or-off thing. Maybe there's a smooth gradation of ensoulment, so that some animals - frogs? - kind-of-have immaterial souls. But that's weird too. What would it mean, to kind of have or halfway have an immaterial soul? Isn't an immaterial soul the kind of thing you either have or don't have? Immateriality doesn't seem like one of these vague properties, like being red or being tall, of which there are gradations and in-between cases. ${ }^{19}$ I don't intend the arguments of the past two paragraphs as a priori metaphysical arguments against dualism. Rather, they constitute a proposed diagnosis of an empirically observed phenomenon: the failure of Descartes, Malebranche, Spinoza, Leibniz, Bayle, Berkeley, Reid, Kant, Hegel, Schopenhauer, et al., up to and including recent substance dualists like Popper and Eccles (1977) and Foster (1991) to develop non-bizarre views of the metaphysics of immateriality. Some of these thinkers are better described as idealists or compromise/rejection theorists than substance dualists, but the mire of issues they faced was the

${ }^{19}$ The same quadrilemma arises if immateriality is regarded as essential to life, as on the types of vitalist theories that were discarded in the early $20^{\text {th }}$ century and on immaterialist views of the "vegetative soul". Nor would successful resolution of the vitalist quadrilemma resolve the core question about mentality, as emphasized by Bayle (1697/1702/1965, "Rorarius"; see also Des Chene 2006). 
same, and my explanation of their attraction to bizarre metaphysics is the same: Common sense opinion about immateriality is a jumble.

You might feel that there exists a well developed substance dualist metaphysics that violates common sense in no major respect. I can't treat every philosopher on a case-by-case basis, but let me briefly mention two: Reid, who enjoys some reputation as a commonsense philosopher, and Descartes, whose interactionist substance dualism has perhaps the best initial intuitive appeal.

Reid's explicit and philosophically motivated commitment to common sense often leads him to refrain from advancing detailed metaphysical views - which is of course no harm to my thesis. However, in accord with my thesis, on those occasions where Reid does develop views on the metaphysics of dualism, he appears unable to sustain his commitment to common sense. On the scope of mentality, Reid is either silent or slides far down toward the panpsychist end: He attributes immaterial souls to vegetables (esp. in 1774-1778/1995, 3.X), but it's unclear whether Reid thinks such immateriality is sufficient for mentality (leading to a view of mentality as radically abundant) or not (in which case Reid did not develop a criterion of non-human mentality and so his view is not "well developed" in the relevant sense). On causal powers, Reid regards material events as causally epiphenomenal: Only immaterial beings have genuine causal power. Physical objects cannot produce motion or change, or even to cohere into shapes, without the regular intervention of immaterial beings (1774-1778/1995; 1788/2010). Reid recognizes that this view conflicts with the commonsense opinions of ordinary people - though he says this mistake of the "vulgar" does them no harm (see 1788/2010, IV.3). Despite his commitment to common sense, Reid explicitly acknowledges that on some issues human understanding is weak and common sense errs (see also 1785/2002, I.1). 
Descartes, too, can't quite keep friendly to common sense regarding causal powers and animal souls. He advocates an interactionist dualist approach to causal powers on which activities of the soul can influence the brain. This view is, perhaps, somewhat less jarring to common sense than some of the other options. But, as noted above, interactionist dualism suggests an odd and seemingly unscientific view of the behavior of neurons, which is perhaps part of why so many of Descartes's dualist successors rejected interactionism. It also, perhaps, requires some contortions to explain how the rational, non-embodied processes of the immaterial soul can be hijacked by drugs and alcohol. ${ }^{20}$ On the distribution of immaterial souls, Descartes goes for Horn 1: Only human beings have minds. Non-human animals, despite their evident similarity to human beings in physiology and in much of their behavior, have no more thought or sensory experience than does a cleverly made automaton (1649/1991). Descartes's opponents imagined Descartes flinging a cat out a window while asserting that animals are mere machines testament to the sharp division between Descartes's and the common person's view about the consciousness of cats. The defenestration of the cat is, or is intended to be, the very picture of metaphysical craziness. ${ }^{21}$ Descartes's interactionist dualism, on inspection, is no great monument of common sense.

I conclude that we have good grounds to believe that any well developed dualist metaphysics of mind will conflict sharply with common sense on some central issues.

vii.

${ }^{20}$ See especially La Mettrie (1748/1994). The power of these two examples is that drugs and alcohol appear to affect the reasoning process itself and not only the passions and bodily movements, contra Descartes's picture of how bodily influences can oppose the immaterial processes of reason $(1649 / 1985$, esp. $\S 47)$.

${ }^{21}$ See Grayling 2005, p. 135, for a recent account of this apocryphal event. 
The third historically important position is idealism, the view that there is no material world at all but only a world of minds or spirits, in interaction with each other or with God, or wholly solipsistic. In the Western tradition, Berkeley (1710-1713/1965), Leibniz (1714/1989), Fichte (1794/1795/1970), and maybe Hegel (1807/1977) are important advocates of this view; some non-Western and mystical thinkers also appear to embrace idealism. ${ }^{22}$ As Berkeley acknowledges, idealism is not the ordinary view of non-philosophers: "It is indeed an opinion strangely prevailing amongst men that houses, mountains, rivers, and, in a word, all sensible objects have an existence, natural or real, distinct from their being perceived by the understanding" (PHK §4). No one, it seems, is born an idealist. They are convinced, against common sense, by metaphysical arguments or by an unusual religious or meditative experience. Idealism also inherits the bizarre choices about causation and the scope of ensoulment that trouble dualist views: If a tree falls, is this somehow one idea causing another, in however many or few minds happen to observe it? Do non-human animals exist only as ideas in our minds or do they have minds of their own; and if the latter, how do we avoid the slippery slope to panpsychism?

The bizarrenesses of materialism and dualism may not be immediately evident, manifesting only when details are developed and implications clarified. Idealism, in contrast, is bizarre on its face.

viii.

${ }^{22}$ See especially the Indian Advaita Vedanta and Yogacara traditions - though these traditions present some of the same interpretative challenges as Hegel, probably involving strands better interpreted as a type of compromise or rejection view. See Deutsch 1969/1973; Deutsch and van Buitenen, eds., 1971; Collins 1998; Lusthaus 2002; Trivedi 2005. 
There might be an alternative to classical materialism, substance dualism, or idealism; or there might be a compromise position. Maybe Kant's transcendental idealism (1781/1787/1998) is such an alternative or compromise, or maybe some sort of Russellian $(1921,1927)$ or Chalmersian (1996) neutral monism or property dualism is. However, I think we could hardly accuse Kant, Russell, or Chalmers of articulating a commonsense view of the metaphysics of mind, even if there are aspects of their views that accord better with common sense than do some of the competitor views. Chalmers, for example, offers no good commonsense answer to the problems of immaterial causation and the scope of immateriality, tentatively favoring epiphenomenalism and panpsychism: All information processing systems, even thermostats, have conscious experience or at least "proto-consciousness", but such immaterial properties play no causal role in their physical behavior. The attractions of Kant, Russell, and Chalmers lie, if anywhere, in their elegance and rigor rather than their commonsensicality.

Alternatively, maybe there's no metaphysical fact of the matter here. Maybe the issue is so ill-conceived that debate about it is hopelessly misbegotten (Carnap 1928/1967, 1932/1959; maybe Searle $1992,2004^{23}$ ). Or maybe asking metaphysical questions of this sort takes us too far beyond the proper bounds of language use to be meaningful. ${ }^{24}$ But this type of view, too, seems bizarre. The whole famous mind-body dispute is over nothing real, or nothing it makes sense to try to talk about? There is no fact of the matter about whether something in you goes beyond the merely physical or material? We can't legitimately ask whether some immaterial part of you might transcend the grave? It's one thing to allow that facts about transcendent

${ }^{23}$ However, despite Searle's self-description I would classify Searle as broadly speaking a materialist (see note 6).

${ }^{24}$ This might seem a broadly Wittgensteinian position, but it's probably not Wittgenstein's own position; see esp. 1945-1949/1958, p. 178, and 1947/1980, vol. 1, §265. 
existence might be unknowable - an agnostic view probably within the bounds of commonsense options - and it's one thing to express the view, as some materialists do, that dualists speak gibberish when they invoke the immaterial soul; but it's quite another thing, a much more radical and unintuitive thing, to say that there is no legitimate sensible interpretation of the dualistmaterialist(-idealist) debate, not even sense enough to allow the materialist coherently to express her rejection of the dualist's transcendent hopes.

ix.

I am making an empirical claim about the history of philosophy and offering a psychological explanation for this putative empirical fact. The empirical claim is that all existing well developed accounts of the metaphysics of mind are bizarre. The psychological explanation is that common sense is incoherent with respect to the metaphysics of mind. Common sense, and indeed I think simple logic, requires that one of four options be true: materialism, dualism, idealism, or a compromise/rejection view. And yet common sense conflicts with each option, either on its face or implicitly as revealed when metaphysical choices are made and implications pursued. If common sense is indeed incoherent in the metaphysics of mind, then the empirical claim can be modally generalized: It is not possible to develop a metaphysics of mind that is both coherent and non-bizarre by the standards of current common sense, if that view involves specific commitments on tricky issues like fundamental ontology, mind-body causation, and the scope of mentality. Call this thesis universal bizarreness. 
Crazyism requires conjoining universal bizarreness with a second thesis, universal dubiety, to which I will now turn. The universal dubiety thesis is just the thesis that none of the bizarre options compels belief.

What is it for a position to be dubious, or - equivalently, as I intend - for it to fail to compel belief? The epistemic psychology of dubiety and belief compulsion is a distractingly thorny affair; I'd prefer to avoid commitment on these issues to the extent I can. So instead of trying to hone a fine point, let me suggest that the arguments below are robust across conceptualizations of dubiety. If the arguments work, they jointly (and perhaps severally) deliver the dubiety of materialism, dualism, idealism, and compromise/rejection views, for most ways of conceptualizing dubiety. Maybe it sounds more pessimistic about a position to say it is "dubious" than that it "fails to compel belief"? If so, I intend a degree of pessimism intermediate between those two formulations.

If it would be helpful, we can talk about credences. I would argue that no one of the four broad-brush positions - materialism, dualism, idealism, or compromise/rejection - merits credence much above 50\%. And I would argue that no moderately specific variant of one of the four views - for example, materialist type-type identity theory or interactionist substance dualism - merits credence even approaching 50\%.

Since the universal dubiety claim is the claim that none of the options compels belief, its strength and plausibility will be relative to the slicing of options. For example, if the options are characterized simply as radical solipsism and the denial of radical solipsism, universal dubiety will be difficult to support. On the other hand, universal dubiety could be asserted of almost any domain if the options are finely enough sliced, including Incredibly Awesome Theory and Incredibly Awesome Theory with a Minor Plausible Twist. For present purposes I assume a 
fairly coarse-grained slicing along roughly the lines suggested above. I also recommend a slicing on which the options differ substantially in which aspects of common sense they violate. Otherwise crazyism would follow too swiftly from bizarreness plus thin slicing.

My thesis concerns only the medium term. I make no claims about the distant future. Boldly extrapolating lines of technological progress, in a hundred years things might look very different. Maybe "the singularity" will have arrived (Kurzweil 2005), and our vastly cognitively superior descendants will laugh good-naturedly at our monkey-mindedness, amazed that beings barely able to think through simple logical problems (e.g., the Wason Selection Task ' Wason 1968) could have generated as much scholarship as we did. Or maybe we will have invented high-bandwidth aerial neural transceivers that enable dozens or thousands or millions of brains to interact as intimately as your right and left hemispheres now interact (Churchland 1981). Common sense and our epistemic situation might change radically. Or they might not. About the $22^{\text {nd }}$ century, I hazard no guesses.

$\mathrm{X}$.

\section{An Argument from Disagreement.}

When experts disagree about some proposition, doubt about that proposition is the most reasonable response, unless the opinions of experts on one side can be disregarded. Experts disagree about basic issues in the metaphysics of mind, such as the truth of materialism vs. dualism vs. idealism vs. a compromise/rejection view. So unless there is good reason to disregard the opinions of experts on all but one side of the dispute, doubt is the most reasonable response. 
Reasons to disregard some group of experts might include: (1.) if that group of experts is a small minority; (2.) if that group of experts is plainly much more biased than the remaining experts; (3.) if that group of experts is much less well-informed or intelligent than the remaining experts; (4.) if that group of experts espouses a view that is patently absurd - not merely "crazy" but so obviously bizarre and undeserving of credence that we can justifiably disregard the opinion of anyone who espouses it. None of these four conditions plausibly apply to dissent within the metaphysics of mind. Contra (1), dissent is widespread. Contra (2), irrational personal and sociological sources of bias seem fairly well distributed among experts occupying a diverse range of positions. (Some readers might regard religious dualists and idealists as more motivated than other philosophers by irrational factors, but even setting theists aside, plenty of dissent remains.) Contra (3), highly intelligent, incredibly well-informed experts endorse very different metaphysical views (e.g., David Chalmers and Daniel Dennett). Contra (4), although probably some views, such as radical solipsism, are so patently absurd as to merit summary dismissal, (a.) given the failure of common sense as a reliable guide, judgments of "patent absurdity" are hard to assess and probably untrustworthy except in the most extreme cases; and (b.) none of the four main metaphysical options is patently absurd even if some of their suboptions are. (Some readers might see idealism as patently absurd, but my argument can survive elimination of that option.)

That's a bird's-eye view on expert disagreement - a perspective from the outside, as it were. We can also consider a view from within the trenches, the perspective from inside commitment to one of the positions. Consider your own case. Presumably you have some opinions about the relative merit of different metaphysical positions. How should you respond to the fact that people you might normally regard as your intellectual peers or even your intellectual 
superiors in such matters - people, that is, who would seem to be at least as well-informed and intellectually capable as you are - disagree with you?

Thomas Kelly (2005) has argued that you may disregard peer dissent when you have “thoroughly scrutinized the available evidence and arguments" on which your disagreeing peer's judgment is based. But we cannot disregard peer disagreement in philosophy of mind on the grounds that this condition is met. The condition is not met. No philosopher has thoroughly scrutinized the evidence and arguments on which all of her disagreeing peers' views are based. The field is too large. Some philosophers are more expert on the literature on a priori metaphysics, others on arguments in the history of philosophy, others on empirical issues; and these broad literatures further divide into subliteratures and sub-subliteratures with which philosophers are differently acquainted. You might be quite well informed overall. You've read Jackson's (1986) Mary argument, for example, and some of the responses to it. You have an opinion. Maybe you have a favorite objection. But unless you are a serious Mary-ologist, you won't have read all of the objections to that argument, nor all the arguments offered against taking your favorite objection seriously. You will have peers whose views are based on arguments which you have not even given cursory consideration, much less thoroughly scrutinized.

Furthermore, epistemic peers, though overall similar in intellectual capacity, tend to differ somewhat in the exact profile of virtues they possess. Consequently, even assessing exactly the same evidence and arguments, convergence or divergence with one's peers should still be epistemically relevant if the evidence and arguments are complicated enough that their thorough scrutiny challenges the upper range of human capacity across several intellectual virtues - a condition that the metaphysics of mind appears to meet. Some philosophers are more 
careful readers of opponents' views, some are more facile with complicated formal arguments, some are more imaginative in constructing hypothetical scenarios, etc., and world-class intellectual virtue in any one of these respects can substantially improve the quality of one's assessments of arguments in the metaphysics of mind. Every philosopher's preferred metaphysical position is rejected by a substantial proportion of philosophers who are overall approximately as well informed and intellectually virtuous as she is, and who are also in some respects better informed and more intellectually virtuous than she is. Under these conditions, Kelly's reasons for disregarding peer dissent do not apply, and a high degree of confidence in one's position is epistemically unwarranted.

Adam Elga (2007) has argued that you can discount peer disagreement if you reasonably regard the fact that the seeming-peer disagrees with you as evidence that, at least on that one narrow topic, that person is not in fact a full epistemic equal. Thus, a materialist might see antimaterialist philosophers of mind, simply by the virtue of their anti-materialism, as evincing less than a perfect level-headedness about the facts. This is not, I think, entirely unreasonable. But it is also fully consistent with still giving the fact of disagreement some weight as a source of doubt. And since your best philosophical opponents will exceed you in some of their intellectual virtues and know some facts and arguments, which they consider relevant or even decisive, which you have not fully considered, you ought to give the fact of dissent quite substantial weight as a source of doubt.

Imagine an array of experts betting on a horse race: Some have seen some pieces of the horses' behavior in the hours before the race, some have seen other pieces; some know some things about the horses' performance in previous races, some know other things; some have a better eye for a horse's mood, some have a better sense of the jockeys. You see Horse A as the 
most likely winner. If you learn that other experts with different, partly overlapping evidence sets and skill sets also favor Horse A, that should strengthen your confidence; if you learn that a substantial portion of those other experts favor B or C instead, that should lessen your confidence. This is so even if you don't see all the experts quite as peers, and this is so even if you treat an expert's preference for B or C as grounds to wonder about her good judgment. The situation in metaphysics of mind is somewhat like this. Admittedly, unlike the typical horse race, your metaphysical opinions are deeply involved with your values and your overall worldview; it's not a local matter of cool indifference. But that consideration cuts both ways. On the one hand, it suggests that we should not entirely discount the possibility that bias really does substantially corrupt large swaths of the profession, including perhaps disproportionately on your opponents' side of questions about the metaphysics of mind. On the other hand, it provides an additional layer of reasons both for self-doubt and for doubt about current trends in the field.

Try this thought experiment. You are shut in a seminar room, required to defend your favorite metaphysics of mind for six hours (or six days, if you prefer) against the objections of Ned Block, David Chalmers, Daniel Dennett, and Saul Kripke. Just in case we aren't now living in the golden age of metaphysics of mind, let's add Kant, Leibniz, Hume, Zhu Xi, and Aristotle too. (First we'll catch them up on recent developments.) If you don't imagine yourself emerging triumphant, then you might want to acknowledge that the grounds for your favorite position might not really be very compelling.

It is entirely possible to combine appropriate intellectual modesty with enthusiasm for a preferred view. Consider everyone's favorite philosophy student: She vigorously champions her opinions, while at the same time being intellectually open and acknowledging the doubt that appropriately flows from her awareness that others think otherwise, despite those others being in 
some ways better informed and more capable than she is. Even the best professional philosophers still are such students, or should aspire to be, only in a larger classroom. So pick a favorite view! Distribute one's credences differentially among the options. Suspect the most awesome philosophers of poor metaphysical judgment. But also: Acknowledge dubiety. ${ }^{25}$

xi.

\section{A No-Method Argument.}

There is no conscious-ometer. Nor should we expect one soon. There is also no material-world-ometer. The lack of these devices problematizes the metaphysics of mind.

Samuel Johnson kicked a stone. Thus, he said, he refuted Berkeley’s idealism (Boswell 1791/1980, p. 333). Johnson's proof convinces no one with an inkling of sympathy for Berkeley, nor should it. Yet it's hard to see what empirical test could be more to the point. Carnap (1928/1967, p. 333-334) imagines an idealist and a non-idealist both measuring a mountain; there is no experiment on which they will disagree. No multiplicity of gauges, neuroimaging equipment, or particle accelerators could give stronger empirical proof against idealism, it seems, than Johnson's kick. Similarly, Smart, in his influential defense of materialism, admits that no empirical test could distinguish materialism from epiphenomenalist substance dualism (1959, p. 155-156); there is no epiphenomenal-substance-ometer.

${ }^{25}$ See Goldberg 2009, forthcoming; Frances 2010, forthcoming; and Kornblith 2010, 2013 for arguments similar to those in this section (though not focusing on the metaphysics of mind in particular); also Christensen 2007. The arguments of this section do not require accepting the "equal weight" view, and I believe they could be endorsed by Kelly (perhaps esp. his 2010). See Fumerton 2010 for a more self-confident perspective on philosophical disagreement. 
Why, then, should we be materialists? Smart appeals to Occam's razor: Materialism is simpler. But simplicity is a complex business. ${ }^{26}$ Arguably, Berkeley's idealism is simpler than either dualism or materialism and solipsism is simpler yet. And anyhow, simplicity is at best one theoretical virtue among several, to be balanced in the mix. Abstract theoretical virtues like simplicity will, I suggest, attach only indecisively, non-compellingly, to the genuine metaphysical contenders. I'm not sure how to argue for this other than to invite you sympathetically to feel the abstract beauties of some of the contending views other than your favorite. Materialism has its beauty. But so does transcendental idealism, and so does neutral monism.

If you're willing to commit to materialism, you might still hope at least for a consciousometer that we could press against a human or animal head to decide among, say, relatively conservative vs. moderate vs. liberal materialistic views of the abundance or sparseness of consciousness in the world. But even this is too much to hope for, I think, in our philosophical lifetimes. Is a frog conscious? That is, does a frog have a stream of phenomenal experience? Is there something it's like to be a frog? If two theorists of consciousness disagree about this matter, no output from an fMRI machine or set of single-cell recordings is likely to resolve their disagreement - not unless they share much more in common than generally is shared by conservatives and liberals about the abundance of consciousness. Similarly intractable, I think, is the dispute about how richly detailed human experience is - about whether, for example, people have constant tactile experience of their feet in their shoes. ${ }^{27}$ If such disputes are intractable, we have no firm grounds of choice between approaches to consciousness that are

${ }^{26}$ E.g., Hempel 1966; Sober 1975; Zellner et al., eds., 2001.

${ }^{27}$ For example, Dennett 1991 vs. Searle 1992. I suspect that most readers will find the medium-term irresolvability of this latter dispute to be less plausible prima facie than in the between-species case. I defend my pessimism about this issue at length in Schwitzgebel 2011. 
relatively liberal (perhaps even as liberal as panpsychism) and approaches that are relatively conservative (perhaps even as conservative as restricting consciousness to adult human beings in their most self-aware moments). Nor, I think, do we have good grounds to deny that liberal and conservative views constitute substantively very different metaphysical pictures. Maybe some disputes among materialists are merely terminological (certain forms of functionalism vs. certain forms of identity theory?). Not the abundance dispute, though; at least not always. Either there's something it's like to be a frog, or there isn't, or somewhere in-between, or the question is somehow broken. These are substantially different positions, each with some ineliminable plausibility and no broadly acceptable means of empirical test. The situation is even worse if we consider a wide variety of hypothetical alien species and artificial human constructions.

Thus I suggest: Major metaphysical issues of mind are resistant enough to empirical resolution that none compel belief on empirical grounds, and none, at a moderate grain of specificity, warrant a degree of credence exceeding that of all competitors; and this situation is unlikely to change in the foreseeable future. Neither do these issues permit resolution by appeal to common sense (which will rebel against all and is probably a poor guide anyway), or by appeal to broad, abstract theoretical considerations. I assume there are no logical selfcontradictions or irresolvable conceptual incoherences in any of these views, at least insofar as they are well developed real contenders. Nor does there seem much hope of a decisive resolution from any combination of these very imperfect approaches.

I see no other means of settling the matter. ${ }^{28}$

xii.

${ }^{28}$ Kriegel 2013 develops a similar argument in more detail, focusing on the ontology of objects as his test case; see also Strawson 2012. 


\section{An Argument from Cosmological Crazyism.}

If a broad-reaching cosmological crazyism is true, then crazyism in the metaphysics of mind is a natural consequence. If we don't know how the universe works, we don't know how the mind fits within it.

I can't defend cosmological crazyism in detail here, but a few remarks can highlight its plausibility. Consider the bizarreness of quantum mechanics and the lack of consensus about its interpretation, including the fact that some interpretations treat mentality as fundamental (such as the many minds view and some versions of the Copenhagen interpretation ${ }^{29}$ ). Consider the bizarreness of relativity theory, perhaps especially the relativistic concept of distance, and the apparent conflict between relativity theory and quantum theory. ${ }^{30}$ Consider that many cosmologies now posit either a creator who set the physical constants or initial conditions at the time of the Big Bang so as to support the eventual occurrence of life, or a vastly unlikely chance setting of those variables, or some sort of dependence of the universe upon our observation of it, or the real existence of a vast number of universes (or regions of this universe) with different physical constants or conditions. ${ }^{31}$ The last of these four views - broadly, multiverse theory - is a recent favorite. Prima facie, multiverse theory is both dubious and bizarre. Here's one among the bizarrenesses: If the number of universes is infinite, or if there is even a single infinite universe of the right sort, then every event of finite probability will occur an infinite number of times (given certain background assumptions about cosmic diversity). The spontaneous

${ }^{29}$ Wigner 1961; Albert and Loewer 1988; Faye 2008.

${ }^{30}$ Or at least the locality restriction central to relativity theory. See Einstein, Podolsky, and Rosen 1935; Bell 1964; Maudlin 1994/2002.

${ }^{31}$ This is the "fine-tuning" issue. See Barrow, Morris, Freeland, and Harper, eds., 2008; Hawking and Mlodinow 2010; Penrose 2010; Stenger 2011. 
congealment, from relatively disorganized matter, of a molecule-for-molecule twin of any living person is often held to have a very tiny but finite probability. ${ }^{32}$ You would, then, be one among an infinite number of actually existing molecule-for-molecule twins of yourself, of diverse origin. (Shades of Nietzsche's eternal return?) Quantum cosmology has also been interpreted as suggesting the backward causation of the history of the universe by our current acts of scientific observation (e.g., Hawking and Mlodinow 2010, p. 140).

Shall we look, then, to religion for non-bizarre cosmologies? That seems an unlikely source. Creation stories, accounts of the afterlife - especially in the hands of those who would attempt to work out the full ontological implications - seem only a source of further bizarreness.

Another difficulty is this: If consciousness can be created within artificial networks manipulated by external users - for example in computer programs run by children for entertainment - and if the beings inside those networks can be kept ignorant of their nature, then there could be beings in the universe who are vastly deluded in fundamental matters of metaphysics. Such beings, perhaps, might think they live in a wide world of people like them when in fact they have three-hour lives, isolated from all but their creator and whatever other beings are instantiated in the same artificial environment. There is, I think, a non-negligible possibility that we (I? you?) are such beings. ${ }^{33}$ Suppose in the year 2200 a new computer game is released, Sims 2012, and it's a huge hit. A hundred million children buy it. Each instance of Sims 2012, when run, creates a hundred thousand actually conscious simulated people, each of

${ }^{32}$ For discussion: Bousso and Freivogel 2007; Page 2008; Carroll 2010; De Simone, Guth, Linde, Noorbala, Salem, and Vilenkin 2010. Such people, or brains, or people-plussections-of-environment, have been dubbed "Boltzmann babies" or "Boltzmann brains" after the $19^{\text {th }}$ century physicist, Ludwig Boltzmann, who argued that in a universe of sufficient size any arbitrary low-entropy event - including presumably the congealment of a person - could be expected to occur by chance (e.g., Boltzmann 1897).

${ }^{33}$ Bostrom 2003; also Chalmers 2010. 
whom thinks she is living in the early $21^{\text {st }}$ century and has an appropriate range of apparent memories and apparent sensory experiences. In reality, these people serve mainly to provide entertaining reactions when, to their surprise, Godzilla tromps through. Possibly, if the economics of technology plays out right, there are many more such simulated beings in the universe than there are non-simulated beings. The details don't matter too much, whether the outside agents are children or historians or scientists, Earthly beings or gods or aliens running an Earth fiction. Might we be Sims of broadly this sort? To think that we are in fact Sims is, of course, crazy. But is the possibility too crazy to figure in a disjunction of live cosmological options? Is it more than one order of magnitude crazier than multiverse theory or the typical well developed religious cosmology? There are no commonsense cosmologies left.

Further support for cosmological dubiety comes from our (apparently) miniscule cosmological perspective. If mainstream scientific cosmology is correct, we have seen only a very small, perhaps an infinitesimal, part of reality. We are like fleas on the back of a dog, watching a hair grow and saying, "Ah, so that's how the universe works!"34

There seems to me to be sufficient cosmological uncertainty to cast into doubt any metaphysics of mind with cosmological commitments. And all well developed metaphysical accounts of the mind will have cosmological commitments, if only in the choice between materialism, dualism, idealism, or a compromise/rejection view. For example, if it might be the case that an immaterial entity fashioned the physical constants, then we cannot justifiably rest assured that materialism is true. If there might really exist universes (not just "possible worlds" but actual universes) so radically different from our own that cognition transpires without the existence of anything we would rightly call material, then materialism is at best a provincial

\footnotetext{
${ }^{34}$ Image inspired by Hume 1779/1947, §II, p. 147-149.
} 
contingency. If we are created within a simulation by outside agents, our experience of objects as necessarily laid out in space and time might be a feature of our programming environment that doesn't reflect the fundamental structure of the universe (Kant meets cyberpunk).

Scientific cosmology is deeply and pervasively bizarre; it is highly conjectural in its conclusions; it has proven unstable over the decades; and experts persistently disagree on fundamental points. Nor is it even uniformly materialist. If materialism draws its motivation from being securely and straightforwardly the best scientific account of the fundamental nature of things, materialists ought to think twice. I focus on materialism, since it is the dominant view in contemporary metaphysics of mind, but similar considerations cast doubt on dualism, idealism, and compromise/rejection views.

xiii.

The most common objection I hear is this: Crazyism is obvious. Given my concerns about peer disagreement, the response is comforting in a way. I have assembled the considerations favoring a view on which we can all agree! Stating the obvious well, and displaying the reasons in support, is one important task of philosophy.

And yet I can't quite accept this picture of what I have done. I don't think most philosophers find it obvious that all coherent, well-developed approaches to the metaphysics of mind conflict with common sense. Perhaps that was Kant's view, especially in the antimonies (1781/1787/1998), but Kant's view of the antimonies is not universally accepted. Scientifically oriented materialists often reject common sense, as I have discussed above, but doing so is entirely consistent with thinking that there might be a commonsensical way to develop dualism. 
Also, it seems to be common argumentative practice in the metaphysics of mind to highlight sharp violations of common sense in views one opposes - idealism, panpsychism, old-school functionalism, eliminative materialism - as though the bizarreness of those views were a weighty consideration against them. This practice is problematic if it is generally agreed that all welldeveloped metaphysical theories sharply violate common sense.

Nor do I think it is widely regarded as obvious that no existing combination of methods could appropriately compel, within our active philosophical lifetimes, high confidence about the broad metaphysics of mind - high confidence, for example, that materialism is true. Some metaphysicians of mind seem highly confident in their views. Maybe most philosophers would accept a weak version of the universal dubiety thesis. Maybe most philosophers would allow at least a smidgen of doubt about the correct broad metaphysics of mind. But the arguments of the past three sections seem to recommend substantially more dubiety than I typically observe in my fellow philosophers, and keep live a substantially wider range of philosophical positions. As a field, we do not fully appreciate, I think, how overmatched we are by the metaphysical task before us - how meager our evidence and how demonstrably insecure our judgment.

xiv.

Certain fundamental questions about the metaphysics of mind can't, it seems, be settled by science, in anything like its current state, or by abstract reasoning. To address these questions we must turn to common sense. If we then have good reason to think that common sense, too, is no reliable guide, we are unmoored. Without common sense as a constraint, the possibilities 
open up, bizarre and beautiful in their different ways; and once open they refuse to shut. This is crazyism. $^{35}$

${ }^{35}$ For helpful comments on drafts or conversation on these topics during the course of writing thanks to Ned Block, Kurt Boughan, Peter Carruthers, Becko Copenhaver, Helen De Cruz, Dan Dennett, Fred Dretske, Sandy Goldberg, Chris Hill, Linus Huang, Bryce Huebner, Jenann Ismael, Hilary Kornblith, Uriah Kriegel, Barry Loewer, Bill Lycan, Pete Mandik, Jozef Muller, Steve Stich, Galen Strawson, Alan Tapper, Nathan Westbrook, Splintered Mind readers, and audiences at University of Cincinnati, Princeton University, Harvard University, and Institut Jean Nicod. 


\section{$\underline{\text { References }}$}

Adams, Fred, and Laura Dietrich (2004). Swampman's revenge: Squabbles among the representationalists. Philosophical Psychology, 17, 323-340.

Albert, David Z., and Barry Loewer (1988). Interpreting the many worlds interpretation. Synthese, 77, 195-213.

Arico, Adam (2010). Folk psychology, consciousness, and context effects. Review of Philosophy and Psychology, 1, 371-393.

Aristotle (4 ${ }^{\text {th }}$ c. BCE/1928). The works of Aristotle, vol VII: Metaphysica, trans. W.D. Ross. Oxford: Oxford.

Armstrong, David M. (1968). A materialist theory of the mind. New York: Routledge. Aydede, Murat (2009). "Pain, philosophical aspects of". In The Oxford companion to consciousness, ed. T. Bayne, A. Cleeremans, and P. Wilken. Oxford: Oxford.

Ayer, A.J. (1967). Metaphysics and common sense. San Francisco: Freeman Cooper.

Baker, Lynne Rudder (1995). Need a Christian be a mind/body dualist? Faith and Philosophy, 12, $489-504$.

Barrow, John D., Simon Conway Morris, Stephen J. Freeland, Charles L. Harper, Jr., eds. (2008). Fitness of the cosmos for life. Cambridge: Cambridge.

Bayle, Pierre (1697/1702/1965). Historical and critical dictionary, trans. R.H. Popkin. Indianapolis: Bobbs-Merrill.

Bechtel, William, and Jennifer Mundale (1999). Multiple realizability revisited: Linking cognitive and neural states. Philosophy of Science, 66, 175-207.

Bell, John S. (1964). On the Einstein Podolsky Rosen paradox. Physics, 1, 195-200. 
Berkeley, George (1710-1713/1965). Principles, dialogues, and philosophical correspondence, ed. C.M. Turbayne. New York: Macmillan.

Block, Ned (1978/2007). Troubles with functionalism. In Consciousness, function, and representation. Cambridge, MA: MIT.

Bloom, Paul (2004). Descartes' baby. New York: Basic Books.

Boltzmann, Ludwig (1887). Zu Hrn. Zermelo's Abhandlung “Ueber die mechanische Erklärung irreversibler Vorgänge”. Annalen der Physik, 296 (2), 392-398.

Bostrom, Nick (2003). Are we living in a computer simulation? Philosophical Quarterly, 53, 243-255.

Boswell, Thomas (1791/1980). Life of Johnson. Oxford: Oxford.

Bourget, David, and David J. Chalmers (forthcoming). What do philosophers believe? Philosophical Studies.

Bousso, Raphael, and Ben Freivogel (2007). A paradox in the global description of the multiverse. Journal of High Energy Physics, 2007 (6) 18.

Boyer, Pascal (2001). Religion explained. New York: Basic Books.

Bratman, Michael (1999). Faces of intention. Cambridge: Cambridge.

Brown, Donald E. (1991). Human universals. Philadelphia: Temple.

Buckwalter, Wesley, and Mark Phelan (2011). Does the S\&M robot feel guilty? Unpublished $\mathrm{ms}$, available at http://experimentalphilosophy.typepad.com

Campbell, Keith (1970). Body and mind. Garden City, NY: Anchor Books.

Carnap, Rudolf (1928/1967). The logical structure of the world and pseudoproblems in philosophy, trans. R.A. George. Berkeley: University of California. 
Carnap, Rudolf (1932/1959). Psychology in physical language. Trans., G. Schick. In Logical positivism, ed. A.J. Ayer. New York: Free press.

Carroll, Sean (2010). From eternity to here. New York: Penguin.

Carruthers, Peter (2005). Consciousness. Oxford: Oxford.

Chalmers, David (1996). The conscious mind. Oxford: Oxford.

Chalmers, David (2010). The character of consciousness. Oxford: Oxford.

Christensen, David (2007). The epistemology of disagreement: The good news. Philosophical Review, 116, 187-217.

Chomsky, Noam (1995). Language and nature. Mind, 104, 1-61.

Chomsky, Noam (2009). The mysteries of nature: How deeply hidden? Journal of Philosophy, $106,167-200$.

Churchland, Paul M. (1981). Eliminative materialism and the propositional attitudes. Journal of Philosophy, 78, 67-90.

Churchland, Paul M. (1984/1988). Matter and consciousness, rev. ed. Cambridge, MA: MIT.

Clark, Andy (2009). Spreading the joy? Why the machinery of consciousness is (probably) still in the head. Mind, 118, 963-993.

Clark, Austen (1994). Beliefs and desires incorporated. Journal of Philosophy, 91, 404-425.

Collins, Randall (1998). The sociology of philosophies. Cambridge, MA: Harvard.

Cohen, L. Jonathan (1992). An essay on belief and acceptance. Oxford: Oxford.

Crick, Francis (1994). The astonishing hypothesis. New York: Charles Scribner's Sons.

De Simone, Andrea, Alan H. Guth, Andrei Linde, Mahdiyar Noorbala, Michael P. Salem, and Alexander Vilenkin (2010). Boltzmann brains and the scale-factor cutoff measure of the multiverse. Physical Review D, 82, 063520. 
Dennett, Daniel C. (1987). The intentional stance. Cambridge, MA: MIT.

Dennett, Daniel C. (1991). Consciousness explained. Boston: Little, Brown, and Company.

Dennett, Daniel C. (2005). Sweet dreams. Cambridge, MA: MIT.

Des Chene (2006). Animal as category: Bayle's "Rorarius”. In The problem of animal generation in early modern philosophy, ed. J.E.H. Smith. Cambridge: Cambridge. Pp. 215-231.

Descartes, René (1649/1985). The passions of the soul. In The philosophical writings of Descartes, vol. 1, trans. J. Cottingham, R. Stoothoff, and D. Murdoch. Cambridge: Cambridge.

Descartes, René (1649/1991). To More, 5 February 1649. In The philosophical writings of Descartes, vol. 3, trans. J. Cottingham, R. Stoothoff, D. Murdoch, and A. Kenny. Cambridge: Cambridge.

Deutsch, Eliot (1969/1973). Advaita Vedānta. Honolulu: University of Hawaii.

Deutsch, Eliot, and J.A.B. van Buitenen (1971). A sourcebook of Advaita Vedānta. Honolulu: University of Hawaii.

DeWitt, Bryce S. (1970). Quantum mechanics and reality. Physics Today, 23 (Sept.), 30-35.

Dretske, Fred (1988). Explaining behavior. Cambridge, MA: MIT.

Dretske, Fred (1995). Naturalizing the mind. Cambridge, MA: MIT.

Edelman, Shimon (2008). Computing the mind. Oxford: Oxford.

Elga, Adam (2007). Reflection and disagreement. Nô̂s, 41, 478-502.

Einstein, A., B. Podolsky, and N. Rosen (1935). Can quantum mechanical description of physical reality be considered complete. Physical Review, 47, 777-780.

Egan, Greg (1994). Permutation city. New York: HarperPaperbacks. 
Faye, Jan (2008). Copenhagen interpretation of quantum mechanics. Stanford Encyclopedia of Philosophy (fall 2008 edition).

Fiala, Brian, Adam Arico, and Shaun Nichols (2011). On the psychological origins of dualism: Dual-process cognition and the explanatory gap. In Creating consilience, ed. E. Slingerland and M. Collard. Oxford: Oxford.

Fichte, Johann F. (1794/1795/1970). Science of knowledge, trans. P.L. Heath and J. Lachs. New York: Appleton-Century-Crofts.

Fodor, Jerry A. (1974). Special sciences (or: The disunity of science as a working hypothesis). Synthese, 28, 97-115.

Fodor, Jerry A. (1987). Psychosemantics. Cambridge, MA: MIT.

Fodor, Jerry A. (1990). A theory of content. Cambridge, MA: MIT.

Foster, John (1991). The immaterial self. London: Routledge.

Frances, Bryan (2010). The reflective epistemic renegade. Philosophy \& Phenomenological Research, 81, 419-463.

Frances, Bryan (forthcoming). Philosophical renegades. In Disagreement, ed. D. Christensen and J. Lackey. Oxford: Oxford.

Frege, Gottlob (1884/1953). The foundations of arithmetic, trans. J.L. Austin. New York: Philosophical Library.

Frege, Gottlob (1918/1956). The thought: A logical inquiry, trans. P.T. Geach. Mind, 65, 289311.

Fumerton, Richard (2010). You can't trust a philosopher. In Disagreement, ed. R. Feldman and T.A. Warfield. Oxford: Oxford.

Gilbert, Margaret (1989). On social facts. Princeton, NJ: Princeton. 
Goldberg, Sanford (2009). Reliabilism in philosophy. Philosophical Studies, 142, 105-117.

Goldberg, Sanford (forthcoming). Disagreement, defeat, and assertion. In Disagreement, ed. J. Lackey and D. Christensen. Oxford: Oxford.

Gopnik, Alison, and Eric Schwitzgebel (1998). Whose concepts are they, anyway? The role of philosophical intuition in empirical psychology. In Rethinking intuition, ed. M.R. DePaul and W. Ramsey. Lanham: Rowman and Littlefield.

Gray, Heather M., Kurt Gray, and Daniel M. Wegner (2007). Dimensions of mind perception. Science, 315, 619.

Grayling, A.C. (2005). Descartes. New York: Walker.

Hawking, Stephen, and Leonard Mlodinow (2010). The grand design. New York: Bantam.

Hegel, Georg Wilhelm Friedrich (1807/1977). Hegel's phenomenology of spirit, trans. A.V. Miller. Oxford: Oxford.

Hempel, Carl G. (1966). Philosophy of natural science. Upper Saddle River, NJ: Prentice Hall. Hempel, Carl G. (1980). Comments on Goodman's Ways of worldmaking. Synthese, 45, 193199.

Hill, Christopher S. (2009). Consciousness. Cambridge: Cambridge.

Hodge, K. Mitch (2008). Descartes' mistake: How afterlife beliefs challenge the assumption that humans are intuitive Cartesian substance dualists. Journal of Cognition and Culture, 8, $387-415$.

Huebner, Bryce (forthcoming). Macrocognition. Oxford.

Huebner, Bryce, Michael Bruno, and Hagop Sarkissian (2010). What does the nation of China think about phenomenal states? Review of Philosophy and Psychology, 1, 225-243. 
Hume, David (1740/1978). A treatise of human nature, ed. L.A. Selby-Bigge and P.H. Nidditch. Oxford: Oxford.

Hume, David (1779/1947). Dialogues concerning natural religion, ed. N.K. Smith. Indianapolis: Bobbs-Merrill.

Humphrey, Nicholas (1992). A history of the mind. London: Chatto \& Windus.

Humphrey, Nicholas (2011). Soul dust. Princeton, NJ: Princeton.

Jackson, Frank (1986). What Mary didn’t know. Journal of Philosophy, 83, 291-295.

Kant, Immanuel (1781/1787/1998). Critique of pure reason, ed. and trans. P. Guyer and A.W. Wood. Cambridge: Cambridge.

Kelly, Thomas (2005). The epistemic significance of disagreement. In Oxford Studies in Epistemology, vol. 1, ed. T.S. Gendler and J. Hawthorne. Oxford: Oxford.

Kim Jaegwon (1998). Mind in a physical world. Cambridge, MA: MIT.

Kirk, Robert (1974). Zombies v. materialists. Proceedings of the Aristotelian Society, Suppl., $48,135-152$.

Kirk, Robert, (2005). Zombies and consciousness. Oxford: Oxford.

Koch, Christof (2012). Consciousness: Confessions of a romantic reductionist. Cambridge, MA: MIT.

Kornblith, Hilary (1998). The role in intuition in philosophical inquiry: An account with no unnatural ingredients. In Rethinking intuition, ed. M.R. DePaul and W. Ramsey. Lanham: Rowman and Littlefield.

Kornblith, Hilary (2010). Belief in the face of controversy. In Disagreement, ed. R. Feldman and T.A. Warfield. Oxford: Oxford. 
Kornblith, Hilary (2013). Is philosophical knowledge possible? In Disagreement and skepticism, ed. D.E. Machuca. New York: Routledge.

Knobe, Joshua, and Jesse Prinz (2008). Intuitions about consciousness: Experimental studies. Phenomenology and the Cognitive Sciences, 7, 67-83.

Kriegel, Uriah (2011). Two defenses of common-sense ontology. Dialectica, 65, 177-204.

Kriegel, Uriah (2013). The epistemological challenge of revisionary metaphysics. Philosophers' Imprint, 13 (2).

Kurzweil, Ray (2005). The singularity is near. New York: Penguin.

La Mettrie, Julien Offray de (1748/1994). Man a machine and man a plant, ed. J. Lieber, trans. R.A. Watson and M. Rybalka. Indianapolis: Hackett.

Lackey, Jennifer, and David Christensen. Oxford: Oxford.

Ladyman, James, and Don Ross (2007). Every thing must go. Oxford: Oxford.

Leibniz, G.W. (1714/1989). The principles of philosophy, or, the monadology. In Philosophical Essays, ed. and trans. R. Ariew and D. Garber. Indianapolis: Hackett. Pp. 213-224.

Levine, Joseph (1983). Materialism and qualia: The explanatory gap. Pacific Philosophical Quarterly, 64, 354-361.

Levine, Joseph (2001). Purple haze. Oxford: Oxford.

Lewis. David K. (1980). Mad pain and Martian pain. In Readings in philosophy of psychology, ed. N. Block. Cambridge, MA: Harvard.

Lewis, David K. (1986). On the plurality of worlds. Malden, MA: Blackwell.

List, Christian, and Philip Pettit (2011). Group agency. Oxford: Oxford.

Lowe, E.J. (2008). Personal agency. Oxford: Oxford.

Lusthaus, Dan (2002). Buddhist phenomenology. New York: RoutledgeCurzon. 
Lycan, William G. (1996). Consciousness and experience. Cambridge, MA: MIT.

Mandik, Pete, and Josh Weisberg (2008). Type Q materialism. In Naturalism, reference, and ontology, ed. C.B. Wrenn. New York: Peter Lang.

Maudlin, Tim (1994/2002). Quantum non-locality and relativity. Malden, MA: Blackwell.

McCauley, Robert N. (2000). The naturalness of religion and the unnaturalness of science. In Explanation and cognition, F.C. Keil and R.A. Wilson, eds. Cambridge, MA: MIT.

McGinn, Colin (1989). Can we solve the mind-body problem? Mind, 98, 349-366.

McGinn, Colin (2004). Consciousness and its objects. Oxford: Oxford.

Metzinger, Thomas (2003). Being no one. Cambridge, MA: MIT.

Montero, Barbara (1999). The body problem. Noûs, 33, 183-200.

Moore, G.E. (1922). Philosophical studies. London: Kegan, Paul, Trench, Trubner.

Moore, G.E. (1925). A defence of common sense. In Contemporary British philosophy, ed. J.H Muirhead. London: George Allen \& Unwin. Pp. 191-223.

Moore, G.E. (1953). Some main problems of philosophy. London: George Allen \& Unwin.

Moore, G.E. (1957). Visual sense data. In British philosophy in mid-century, ed. C.A. Mace. London: George Allen \& Unwin.

Murphy, Nancey (2006). Bodies and souls, or spirited bodies? Cambridge: Cambridge.

Nietzsche, Friedrich (1883-1888/1967). The will to power, trans. W. Kaufmann and R.J. Hollingdale. New York: Vintage.

Page, Don N. (2008). Return of the Boltzmann brains. Physical Review D, 78, 063536.

Patterson, Sarah (2005). Epiphenomenalism and occasionalism: Problems of mental causation, old and new. History of Philosophy Quarterly, 22, 239-257.

Penrose, Roger (2004). The road to reality. New York: Knopf. 
Penrose, Roger (2010). Cycles of time. London: Bodley Head.

Phelan, Mark, Adam Arico, and Shaun Nichols (forthcoming). Thinking things and feeling things: On an alleged discontinuity in folk metaphysics of mind.

Popper, Karl R., and John C. Eccles (1977). The self and its brain. Berlin: Springer.

Putnam, Hilary (1965). Psychological predicates. In Art, mind, and religion, ed. W.H. Capitan \& D.D. Merrill. Liverpool: University of Pittsburgh Press / C. Tinling.

Ramsey, William (2006). Multiple realizability intuitions and the functionalist conception of mind. Metaphilosophy, 37, 53-73.

Reck, Erich (2005). Frege on numbers: Beyond the Platonist picture. Harvard Review of Philosophy, 13 (2), 25-40.

Reid, Thomas (1774-1778, 1995). Materialism. In Thomas Reid on the animate creation, ed. P. Wood. University Park, PA: Pennsylvania State University.

Reid, Thomas (1785/2002). Essays on the intellectual powers of man, ed. D.R. Brookes. University Park, PA: Pennsylvania State University.

Reid, Thomas (1788/2010). Essays on the active powers of man, ed. K Haakonssen and J.A. Harris. University Park, PA: Pennsylvania State University.

Richert, Rebekah A., and Paul L. Harris (2006). The ghost in my body: Children's developing concept of the soul. Journal of Cognition and Culture, 6, 409-427.

Robbins, Philip and Anthony I. Jack (2006). The phenomenal stance. Philosophical Studies, 127, 59-85.

Rosenthal, David M. (2005). Consciousness and mind. Oxford: Oxford.

Russell, Bertrand (1921). The analysis of mind. London: George Allen \& Unwin.

Russell, Bertrand (1927). The analysis of matter. London: Paul, Trench, and Trubner. 
Schwitzgebel, Eric (2011). Perplexities of consciousness. Cambridge, MA: MIT.

Schwitzgebel, Eric (in preparation-a). If materialism is true, the United States is probably conscious. Available at: http://faculty.ucr.edu/ eschwitz

Schwitzgebel, Eric (in preparation-b). The tyrant's headache. Available at: http://faculty.ucr.edu/ eschwitz

Searle, John (1980). Minds, brains, and programs. Behavioral and Brain Sciences, 3, 417-457.

Searle, John (1984). Minds, brains, and science. Cambridge, MA: Harvard.

Searle, John (1992). The rediscovery of the mind. Cambridge, MA: MIT.

Searle, John (1995). The construction of social reality. New York: Free Press.

Searle, John (2004). Mind. Oxford: Oxford.

Searle, John (2010). Making the social world. Oxford: Oxford.

Shapiro, Lawrence A., and Thomas W. Polger (2012). Identity, variability, and multiple realization in the special sciences. In New perspectives on type identity, ed. S. Gozzano and C. Hill. Cambridge: Cambridge.

Slingerland, Edward, and Maciej Chudek (2011). The prevalence of mind-body dualism in early China. Cognitive Science, 35, 997-1007.

Smart, J.J.C. (1959). Sensations and brain processes. Philosophical Review, 68, 141-156.

Sober, Elliott (1975). Simplicity. Oxford: Oxford.

Stenger, Victor J. (2011). The fallacy of fine-tuning. New York: Prometheus.

Stich, Stephen (1983). From folk psychology to cognitive science. Cambridge, MA: MIT.

Stoljar, Daniel (2010). Physicalism. Oxford: Routledge.

Strawson, Galen (2012). Real naturalism. Proceedings of the American Philosophical Association, 86 (no. 2), 125-154. 
Strawson, P.F. (1959). Individuals. London: Methuen.

Strawson, P.F. (1985). Skepticism and naturalism. New York: Columbia.

Sytsma, Justin M., and Edouard Machery (2010). Two conceptions of subjective experience. Philosophical Studies, 151, 299-327.

Tononi, Guilio (2004). An information integration theory of consciousness. BMC Neuroscience, $5(42)$.

Trivedi, Saam (2005). Idealism and Yogacara Buddhism. Asian Philosophy, 15, 231-246.

Tuomela, Raimo (2007). The philosophy of sociality. Oxford: Oxford.

Tye, Michael (1995). Ten problems of consciousness. Cambridge, MA: MIT.

Tye, Michael (2009). Consciousness revisited. Cambridge, MA: MIT.

Van Fraassen, Bas C. (1980). The scientific image. Oxford: Oxford.

Wallace, David (2008). Philosophy of quantum mechanics. In The Ashgate companion to contemporary philosophy of physics, ed. D. Rickles. Hants, England: Ashgate. Pp. 1698.

Wason, P.C. (1968). Reasoning about a rule. Quarterly Journal of Experimental Psychology, $20,273-281$.

Weinberg, Jonathan M., Chad Gonnerman, Cameron Buckner, and Joshua Alexander (2010). Are philosophers expert intuiters? Philosophical Psychology, 23, 331-355.

Wigner, Eugene P. (1961). Remarks on the mind-body question. In The scientist speculates, ed. I.J. Good, A.J. Mayne, and J.M. Smith. London: Heinemaan. Pp. 284-302.

Wilson, Robert A. (2004). Boundaries of the mind. Cambridge: Cambridge. Wittgenstein, Ludwig (1945-1949/1958). Philosophical investigations, trans. G.E.M. Anscombe. New York: Macmillan. 
Wittgenstein, Ludwig (1947/1980). Remarks on the philosophy of psychology, vol. 1, trans.

G.E.M. Anscombe. Chicago: University of Chicago.

Yablo, Stephen (1987). Identity, essence, and indiscernibility. Journal of Philosophy, 84, 293314.

Zellner, Arnold, Hugo A. Zeuzenkamp, and Michael McAleer, eds. (2001). Simplicity, inference, and modeling. Cambridge: Cambridge.

Zuckerman, Phil (2007). Atheism: Contemporary numbers and patterns. In The Cambridge companion to atheism, ed. M. Martin. New York: Cambridge. 